\title{
La velocidad de los cuerpos: mercado, distopía y desecho en Los días de la peste, de Edmundo Paz Soldán
}

Recibido: 01/10/2018| Revisado: 27/11/2018| Aceptado: 03/12/2018

DOI: 10.17230/co-herencia.16.30.7

\author{
Jesús Montoya Juárez* \\ jesusmontoya@um.es
}

Resumen Edmundo Paz Soldán es uno de los narradores latinoamericanos que de manera más audaz ha visitado el tópico del devenir simulacro de lo real y la transformación que la proliferación tecnológica de nuestro siglo provoca en la psique humana. En sus obras podemos leer una dominante arqueológica, frecuente en el género distópico, más allá de que sus ficciones, tal vez a excepción de Iris y Las visiones, no puedan etiquetarse de ciencia ficción. Me centro en este artículo en su última novela publicada. Los días de la peste puede, en principio, leerse como una vuelta al realismo tras un ciclo narrativo que visita la ciencia ficción; no obstante, en ella, la presencia material de los cuerpos, la reflexión sobre su condición de objeto problemático, como ocurría en Iris o en Las visiones, resulta obsesiva y central. La novela parece abordar la pregunta que, entre otros, se hacía Santiago Alba Rico en su ensayo Ser o no ser (un cuerpo) (2017): ¿cuál es la velocidad de los cuerpos hoy? ¿Cuál es su estatuto bajo el capitalismo contemporáneo? ¿Qué tienen que decir o reclamarnos? Paz Soldán, así, ofrece en la novela el colofón a una reflexión sobre la condición del cuerpo y la subjetividad en nuestro tiempo, articulado desde la ciencia ficción, y un realismo contemporáneo preñado de sus tópicos.

\section{Palabras clave:}

Distopía, cuerpo, poshumanismo, neoliberalismo, desecho, cultura material, literatura latinoamericana, ciencia ficción.
* Doctor en Literatura hispanoamericana por la Universidad de Granada. Profesor asociado, Departamento de Literatura Española, Teoría de la Literatura y Literatura Comparada, Universidad de Murcia, España. ORCID: 0000-00018846-9564. 


\title{
The speed of bodies: market, dystopia and waste in Los días de la peste, by Edmundo Paz Soldán
}

\begin{abstract}
Edmundo Paz Soldán is one of the Latin American narrators who has most daringly explored the topic of the transformation of the real into simulacrum as well as the change that technological proliferation that the current century brings about in human psyche. In his works an archaeological predominant element can be read, which is frequent in the dystopian genre, irrespective of whether his fictions, perhaps except for Iris and Las visiones, cannot be labeled as science fiction. In this paper I focus on his last published novel. Los días de la peste can, in principle, be construed as a return to realism after a narrative cycle exploring science fiction. Nevertheless, in this novel, the material presence of bodies, the reflection on their condition as problematic objects, as it was the case in Iris or in Las visiones, is obsessive and central. The novel seems to address the question that was raised by Santiago Alba Rico, among others, in his essay Ser o no ser (un cuerpo) (2017): What is the speed of bodies today? What is their status under contemporary capitalism? What do they have to say or claim? Paz Soldán thus offers in the novel the colophon to a reflection on the condition of the body and subjectivity in our time, articulated from science fiction, and a contemporary realism fraught with his topics.
\end{abstract}

\section{Keywords:}

Dystopia, body, posthumanism, neoliberalism, waste, material culture, Latin American literature, science fiction.

\section{Introducción: distopía y realismo}

En "Las antinomias de la posmodernidad", incluido en Las semillas del tiempo (1994), Fredric Jameson discurría sobre la represión de la historicidad en la época posmoderna. En el texto que cito, Jameson valoraba la ciencia ficción como un género particularmente valioso para reflexionar sobre el deseo utópico, a la vez que permitía la conexión del lector con la historia que desemboca en su presente, al proyectarla al futuro. Concluye el crítico estadounidense que, en la ciencia ficción, brilla con fuerza algo que reclama con vehemencia al arte: la elaboración de una cartografía cognitiva del presente, que permite al individuo iniciar la tarea de establecer relaciones simbólicas entre su realidad y la totalidad social a la que pertenece y, de ese modo, construir posibles programas políticos para su emancipación 
(cfr. Jameson, 2000). En Archaeologies of the Future (2005), Jameson ahonda en esa misma idea. Lo interesante de la ciencia ficción radica en el tipo de lector que demanda, uno que examina las ruinas del pasado (nuestro presente, por ejemplo, en este siglo xxI) en ese futuro, como quien trabaja en un yacimiento, un arqueólogo que aísla objetos y traza líneas de sentido entre ellos, en aras de reconstruir, así, un relato que permita una lectura política de sociedades como las que muchos habitamos en la actualidad.

Esta dominante arqueológica deviene, en los últimos años, cada vez más frecuente en un buen número de poéticas a uno y otro lado del Atlántico, que se complacen estéticamente en subrayar los restos inasimilables, obsoletos o heterocrónicos en los paisajes contemporáneos (cfr. Montoya Juárez, 2013). En la última década y media, la imaginación distópica ha colonizado la silueta de numerosos proyectos narrativos anclados en un siglo XxI globalizado. Ello no es extraño, pues como sugieren Gordin, Tilley y Prakash,

[...] en este universo sujeto a una entropía creciente, uno encuentra que hay muchos más [...] modos de generar distopía que utopía. Y, crucialmente, la distopía adopta el aspecto frecuente de la experiencia vivida. La gente percibe su medio como distópico [...] (2010, p. 2).

Mientras la utopía "nos lleva a un futuro para juzgar el presente, la distopía nos ubica directamente en la oscura y deprimente realidad, para invocar un futuro terrible" (Gordin et al., 2010, p. 2), cada vez más próximo. ${ }^{1}$

En una entrevista de 2016 a propósito de la publicación del libro de cuentos Las visiones (2016), Edmundo Paz Soldán se suma a esta idea, aseverando, con respecto a la ciencia ficción, lo siguiente:

Creo que de la misma manera que en las últimas décadas la novela policial ha ido desarrollándose hasta convertirse en la gran novela social de nuestro tiempo, la ciencia-ficción ha ocupado en parte la función del realismo, puesto que en la medida que las nuevas tecnologías se han ido convirtiendo en elementos centrales de nuestra vida cotidiana alguien debía hacerse cargo de la reflexión en torno a lo que significa

1 La más célebre defensa del género distópico como realista, en los últimos años, corre a cargo - tal vez- de Mark Fisher, quien apunta, a propósito de The Children of Men, de Alfonso Cuarón, que la distopía, género político de nuestro tiempo, lidia de la mejor forma el sentido de realidad de nuestra época (cfr. Fisher, 2016). 
vivir en una sociedad en la que la presencia de las máquinas se hace cada vez más ubicua y esta reflexión pertenece a la ciencia-ficción. Lo que sucede es que antes esta reflexión podía proyectarse hacia el futuro, pero el tiempo de las máquinas inteligentes es el nuestro y, por tanto, creo que es o debería ser normal que en medio de una novela realista se encontrara una escena que, tiempo atrás, habríamos definido de ciencia-ficción (en Iglesia, 2016).

En efecto, en la obra reciente de Paz Soldán, uno de los narradores latinoamericanos que con más insistencia ha visitado el tópico del devenir simulacro de lo real y la penetración de la tecnología en la vida cotidiana, podemos leer esta misma dominante arqueológica, propia del género distópico, más allá de que sus novelas y libros de cuentos, salvo Iris y Las visiones, no puedan catalogarse como de ciencia ficción. A mi modo de ver, esta dominante ha sido particularmente visible en los últimos años, conformando un ciclo que, hasta el momento, ha dado dos novelas (Iris, 2014, y Los días de la peste, 2017a) y el volumen de relatos ya citado (Las visiones, 2016).

Me he ocupado con anterioridad por extenso de Iris (cfr. Montoya Juárez, 2017). Me centro, en este artículo, en su, hasta ahora, última novela publicada. A lo largo de estas páginas apunto algunas ideas a propósito de esta obra, examinada a la luz de problemáticas centrales en la producción narrativa del autor.

En primer lugar, si bien Los días de la peste supone un inesperado regreso a la temática nacional tras una serie de novelas de tendencia centrífuga (cfr. Montoya Juárez, 2011), ${ }^{2}$ problematizamos aquí esta afirmación, mostrando en qué medida continúa siendo marca identitaria de su obra la hibridación de lo local y lo global, tanto en lo relativo a los imaginarios narrativos que despliega la novela, como en la serie de referencias intertextuales y transmediales invocadas por el texto.

En segundo lugar, aunque Los días de la peste se ha leído también como una vuelta al realismo tras un excurso por la ciencia ficción, esta novela carcelaria y pestífera, aparentemente ambientada en Bolivia, leída desde el conjunto de toda la producción del autor, dialoga perfectamente con determinadas problemáticas afines al

2 Por ejemplo, Los vivos y los muertos (2009), Norte (2011) o Iris. 
género. Formulo, entonces, la segunda tesis que desarrollo: a pesar de que de la novela desaparezcan los híbridos biológico-maquínicos y de que pierdan relevancia los artefactos tecnológicos, en ella la presencia material de los cuerpos resulta quizás aún más obsesiva y central que en otros textos del autor. En este sentido, Los días de la peste no parece el inicio de un ciclo, sino, por el contrario, el colofón de una reflexión que acomete buena parte de su producción narrativa previa.

Así, la pregunta que arroja la novela podría ser la que se plantea Santiago Alba Rico en su ensayo Ser o no ser (un cuerpo) (2017): ${ }^{3}$ ¿cuál es la velocidad de los cuerpos hoy? ¿Cuál es su estatuto en una época de máxima aceleración del tiempo capitalista?

Y la respuesta a la que aparentemente apunta la novela, desde una actitud no nostálgica respecto de formas de concepción de la subjetividad modernas, estriba en la insistencia en la idea de que el cuerpo sigue siendo el depósito de las contradicciones del capitalismo: la conflictiva relación que sostenemos con los cuerpos nos define como especie, mas su destrucción, su abandono, también son la destrucción y el abandono de aquello que más íntimamente nos representa.

A lo largo de la última década y media al menos, la obra del autor boliviano, como quizás ninguna otra en nuestra lengua, se ha ocupado de transcribir las formas en que los procesos globalizadores y la tecnología reconfiguran el binomio mente/cuerpo en nuestro tiempo; un binomio que, al ser invocado en numerosos pasajes de sus ficciones, suele proyectar heterocronías en las que se solapan historias locales y diseños globales, que subrayan la obsolescencia inscrita en la piel del cuerpo, sobrepujado por la presión que ejerce sobre él la velocidad de escape del neoliberalismo (cfr. Dery, 1998).

Si leemos la novela contra el background de la producción narrativa previa de Paz Soldán, la omnipresencia de los cuerpos convertidos en desecho en Los días de la peste se nos ofrece como un

3 En el fondo, una pregunta en la línea de las que se hacían teóricos como Mark Dery (en Velocidad de escape. La cibercultura en el final de siglo, 1998) y, antes, Paul Virilio (en Cibermundo, ¿una política suicida?, 1997) y, antes que él, Marshall McLuhan (en Comprender los medios de comunicación, 1996), y todavía antes que él, Walter Benjamin (en Experiencia y pobreza, 2003): ¿qué parte de nuestra humanidad dejamos en la casa de empeño por una ínfima parte de su valor para que se nos sirva una vez más la pequeña moneda de lo actual? El cuerpo, aquí, es, antes que un símbolo, el campo de pruebas que analiza la ficción. 
cuestionamiento del horizonte que ciertas teorías del poshumanismo han puesto de relieve. Y es que el cuerpo, experimentado en su debilidad y contingencia, agredido, modificado o abandonado a su suerte, supone el más llamativo resto arqueológico de nuestro presente; por eso es, particularmente en Los días de la peste, el absoluto protagonista.

\section{Los días de la peste: una "vuelta" global a Bolivia}

Como hemos apuntado, buena parte de los reseñistas celebran Los días de la peste como un inesperado regreso a Bolivia ${ }^{4}$ en la narrativa del autor. Tal vez se olvida que Iris, su novela inmediatamente anterior, asignable al género de la ciencia ficción y ambientada en una isla imposible, en un futuro lejano, es una de las novelas más "bolivianas" de Paz Soldán. Como he analizado en otro trabajo (cfr. Montoya Juárez, 2017), en dicha novela el autor subsana una deuda con la narrativa de la minería, rindiendo un homenaje a Aluvión de fuego (1935), de Óscar Cerruto.

Resulta relevante para el proyecto narrativo de Paz Soldán el modo original que tiene de trabajar sobre las tradiciones narrativas nacionales y latinoamericanas. Lo hace con la novela del dictador, en El delirio de Turing (2003); con la novela minera, en Iris, y, ahora, con la novela carcelaria, en Los días de la peste, tradición que tiene un peso importante en la narrativa del continente, como apunta en su estudio sobre esta obra José Manuel Camacho (2018). ${ }^{5}$ No obstante, como veremos, este aparente localismo de Los días de la peste está fuertemente atravesado por referentes globales que conviene subrayar.

La novela narra el cruce de dos procesos de contaminación —-dos plagas- en el interior de lo que Goffman llamaría una "institución

4 Sus novelas y cuentos desde 2009 han estado ambientadas en escenarios alejados del país: Los vivos y los muertos, Norte, Iris y una parte de los cuentos incluidos en el volumen Billie Ruth (2012).

5 Camacho rememora, en su ensayo, obras clave de la tradición: El túnel de Ernesto Sábato, El viaje del loco Tafur de Mario Mendoza, El último filo de Renato Prada Oropeza, Match Ball de Antonio Skármeta, La mujer del policía de Sergio Gómez, Cárcel de árboles de Rodrigo Rey Rosa o Transportes González e Hija de María Amparo Escandón, entre otros. Agradezco al doctor Camacho la generosidad de haberme facilitado la conferencia que leyó en la primavera de 2018 en Olomouc, inédita hasta el momento. Para una lectura política de la novela resultará muy recomendable la lectura del trabajo de Camacho (2018). 
total" (Goffman, 1972, p. 13) fallida, una prisión en un territorio denominado "Los Confines", una provincia en un país innominado que podemos asumir como Bolivia.

El primer proceso consiste en la expansión de una secta que pretende ser usada por el Presidente y sus seguidores para obtener un rédito político, que acaba siendo prohibida por las autoridades locales, y que provoca finalmente un motín en la prisión.

De nuevo, tal vez sea la ciencia ficción el género contemporáneo que mejor marida con el análisis de las implicaciones políticas del hecho religioso. Clásicos como Fundación (1951), de Asimov; "La estrella" (1955), de Arthur C. Clarke, y, sobre todo, Dune (1965), de Frank Hebert, son ejemplos donde lo religioso desempeña un papel clave. Acaso podemos leer las deidades fantásticas que aparecen en Los días de la peste como un eco o influjo del género fanta-científico, ${ }^{6}$ como ocurre en Iris.

No obstante, como podríamos leer igualmente en esta novela anterior, las relaciones entre religión, enfermedad y poder $^{7}$ también suponen un diálogo fuerte con la tradición narrativa del Continente. Si el episodio de Orlewen, el líder irisino elegido para liderar la revolución contra la potencia colonizadora, recordaba por momentos a determinados pasajes del comienzo de El reino de este mundo (1949), de Alejo Carpentier, lo mismo puede decirse de la rebelión en curso en el interior de la Casona.

Más allá de estos influjos, religión y enfermedad como temas literarios han estado conectados también en la literatura pestífera desde antiguo. La peste se ha explicado como una maldición: desde la Atenas de Tucídides, o desde la Tebas de Sófocles, ha sido una de las plagas que castigan los pecados de los hombres. Otro de los referentes de la novela es, obviamente, la obra de Daniel Defoe, Diario del año de la peste, de 1722 (1969), que ficcionaliza el despliegue de la plaga que acontece en Londres, en 1665. El diario ficticio que es esta

6 Proveamos una definición del adjetivo "fanta-científico" como relativo a la fanta-ciencia o ciencia ficción. El término está en circulación en español desde comienzos del siglo xx, y fue popularizado en literatura por, entre otros, Leopoldo Lugones. Resulta análogo al de ciencia ficción, de origen anglosajón. Uso ambos términos a lo largo del artículo indistintamente.

7 Punto de inflexión que Camacho lee en Los días de la peste con respecto a la tradición de la literatura carcelaria latinoamericana (cfr. Camacho, 2018). 
novela se detiene en las formas heterodoxas de la religión, fruto del pensamiento mágico que surge como respuesta emocional a la crisis, con la subsecuente proliferación de curanderos, adivinos y otros personajes. Algunas de las visiones que Defoe recoge del testimonio ficticio de los delirios de los enfermos aparecen en la novela de Paz Soldán, versionadas de acuerdo con la mitología de Ma Estrella, divinidad que se adora en Los Confines. ${ }^{8}$

El segundo proceso que antes mencionábamos, la expansión de una extraña enfermedad para la que no hay cura, hace pensar inmediatamente de nuevo en un referente global. La novela remite al episodio del Ébola de hace unos años, que los flujos informacionales hicieron circular de acuerdo con una retórica del pánico alimentada por lo que Naomi Klein definió como "doctrina del shock" (cfr. Klein, 2007).

La Casona es la cárcel de una provincia alejada de la capital, en un país innominado que, más precisamente que con Bolivia, podríamos relacionar con el espacio zonal de Río Fugitivo9 (el narrador nos cuenta que el personaje de Antuan, el preso escultor, "tomó un tren y al tercer día llegó a Los Confines y lo atrajo el río serpenteante que lo atravesaba” —2017a, p. 33-). Lo local, lo boliviano, en realidad, aparece ante todo en la novela como efecto de lenguaje. Pese a no referirse su nombre en sus páginas, el argot que manejan los presos (que en muchos casos narran en primera persona), pero también los diferentes narradores omniscientes ${ }^{10}$ (existen hasta treinta y un diferentes, protagonizando pasajes intercalados y agrupados en las tres secciones de esta complejísima y faulkneriana obra), se inspiran en la coba, lengua de germanías manejada por los presos de las cárceles bolivianas, que estudió en los años ochenta

8 Camacho, en su estudio ya citado, refiere una serie completa de referentes o intertextos que pueden operar en la lectura que hace del motivo pestífero Edmundo Paz Soldán, entre ellos, obviamente, Gabriel García Márquez, autor en el que Camacho es un destacado especialista.

9 Zona literaria de varias novelas pazsoldanianas anteriores (Sueños digitales, El delirio de Turing, La materia del deseo [2002]) que toma el nombre de la Cochabamba que imagina para sus cuentos policíacos Roby, el protagonista de la novela homónima Río Fugitivo (1998).

10 Narradores omniscientes que presentan distintos grados de familiaridad, empleando el estilo indirecto libre, con la óptica de los personajes que protagonizan cada escena. 
el tristemente desaparecido Víctor Hugo Viscarra. 11 "Quivo", "wawa”, "turril", "patapila", "hacerse el tigre”, "hacerse la puta", "cogotero", "pepas”, “torcis”, “cafisho", “socapar”, "anticucho”, "bisnes”, “telo”, y un largo etcétera se combinan, también, con neologismos construidos ad hoc para esta jerga. Así, "tonchi" (término presumiblemente adaptado del italiano "escarabajo" para designar la droga — la "sustancia violeta"-), "putapariós" (insectos que ya aparecían en Iris o Las visiones) o el más poético "desnublar", entre otros, no figuran recogidos en el diccionario de la Real Academia Española, ni siquiera como americanismos, y son moneda común, sin embargo, en la novela.

El autor reconoce abiertamente haberse inspirado en la prisión de San Pedro. El influjo es fuerte. La cárcel de La Paz provee noticias, anécdotas, que, sintetizadas y modificadas por la imaginación literaria, es plausible que ofrezcan material para determinados motivos y personajes. No obstante, no hay una intención, por parte del autor, de fijar ningún hecho histórico como relevante en la novela. Tampoco hay marca temporal alguna que permita asignarle un tiempo externo preciso. Aparentemente, puede anclarse a nuestro tiempo: "internet", "drones", "implantes", "bótox", "cirugía” son comunes en la novela. La analogía con algunos acontecimientos reales puede hacer pensar en que el mandato de Lucas Otero, gobernador de la Casona, pueda vincularse al del general Luis Cerruto, gobernador a cargo en el periodo en que acontecieron los mayores escándalos de corrupción en la historia reciente de San Pedro: visitas de turistas extranjeros al penal, alquileres de celdas para estancias, prostitución, venta masiva de droga producida en laboratorios clandestinos tanto a reclusos como a visitantes, etc. ${ }^{12}$

Otro referente fundamental para la novela es Marching Powder (2003), libro de no ficción inspirado en la presencia de su autor como inquilino de San Pedro. El libro de Rusty Young ha influido en la imagen que se ofrece de la prisión, que Paz Soldán afirma ${ }^{13}$ no haber

11 Recogido en su obra Coba: lenguaje secreto del hampa boliviana (1981).

12 Un alcaide que, paradójicamente, fue encerrado en la propia San Pedro en el año 2015, condenado por corrupción. La identificación con hechos reales no es fácil ni interesante; los paralelismos tienen antes que ver con el ambiente de San Pedro que con referentes más o menos concretos.

13 En una entrevista en vídeo realizada para el periódico boliviano El Deber (2017b). 
querido nunca visitar para que no interfiriera en su proyecto. El británico Thomas McFadden, preso en San Pedro esos años, protagonista del documental de Young, acaso podría tener su lejana analogía en Glauco, el preso "gringo" de la Casona.

El culto a Ma Estrella, apodada por sus detractores "La Innombrable", deidad de la venganza que aparece en las tallas y dibujos con un cuchillo entre los dientes, convive con la ortodoxia cristiana en la Casona. A "La Innombrable" se le ofrece toda clase de sacrificios animales, e inclusive humanos, como las "santitas", cráneos de cerámica o reales que adornan los altares improvisados de la prisión. El rito, de nuevo, nos remite al ritual de las "ñañitas" (así llamadas por carecer las calaveras de nariz), que se da en ciertas prácticas religiosas sincréticas, de influencia indígena, vigentes en Bolivia.

Sin embargo, de nuevo, esa nota de aparente color local se halla atravesada por referencias globalizadas. Afirma Paz Soldán que, para este último período de su narrativa (de Iris en adelante), fue decisivo un viaje que hizo a la India en 2012. En Ma Estrella, a quienes sus fieles rezan la oración de los "cincuenta y ocho nombres de Ma Estrella" (Paz Soldán, 2017a, p. 39) (mismo número que la letanía lauretana), la iconografía cristiana se confunde con la de la diosa Kali, de aspecto aterrador y habitualmente representada con un cuchillo en la mano.

Otra influencia declarada por el propio autor remite a la India: en concreto, al libro Nueve vidas, de William Darlymple (2010). Una de las historias de este libro es la de una monja jainista que, tras perder a una compañera con la que recorría los caminos de la India practicando la ahimsa (o cuidado meticuloso para no matar ninguna vida), enferma ella misma de tuberculosis y malaria, y decide emprender la senda del sallekhana, una muerte ritual a través de un ayuno lento y sistemático. ${ }^{14}$

El jainismo sirve de modelo para construir la fe de Rigo, tal vez el personaje más interesante de la novela. También este ha perdido a Marilia, su compañera, doctora en un "hospital de pájaros", que resulta un guiño al hospital homónimo que aparece en Iris y en uno

14 Como es sabido, el jainismo plantea, básicamente, la austeridad máxima, una religiosidad sin dioses, la creencia en el ciclo de las reencarnaciones y el respeto a todo ser vivo. 
de los relatos de Las visiones. Rigo expía la culpa por haberla asesinado o, en el mejor de los casos, ayudado a bienmorir, tapándole la cara con una almohada. Rigo, ese "yo" múltiple en busca de su autonegación (o autodisolución) en una comunidad esquizoide interior al individuo, pretende — a su manera - el sallekhana para expiar su culpa, al cuidar de los enfermos sin protección, persiguiendo ser contaminado con el virus letal que circula por la cárcel: "Dios Mayor de la Transfiguración, no me salves. Tómanos cuando termine esto a cambio de lo que hicimos, susurramos. De lo que hice. Restablece el equilibrio pero déjanos luchar contra la plaga" (Paz Soldán, 2017a, p. 302). ${ }^{15}$

El plural en el discurso de Rigo, en momentos de particular debilidad, como vemos en la cita, desaparece. El viejo "yo" emerge sobre todo cuando se deja llevar por el dolor y la memoria. Esa disolución del "yo" parece ser, en la novela, una de las formas de adaptarse a la locura que se vive en el penal: el reparto de juego entre la mente y las diferentes partes de un cuerpo que se observan como no pertenecientes al sujeto, construido de acuerdo con fórmulas identitarias vinculadas a lo poshumano, se propone, no obstante, como una amarga utopía.

En este sentido, la novela propone ir un paso más allá en la exploración de la subjetividad poshumana que acomete en novelas anteriores el propio Paz Soldán. Con el personaje de Rigo, la novela construye, en medio del caos imperante, una fórmula identitaria como salida para el self en un contexto apocalíptico, una salida que no se resuelve positivamente y se revela inútil, si bien permite una lucidez mayor para comprender el funcionamiento del entorno caótico en que viven los personajes. Rigo es, sin duda, uno de los hallazgos más valiosos de la novela.

\section{Cuerpos, mercado y desecho en Los días de la peste}

En las páginas que siguen pretendo analizar la reflexión sobre las valencias de lo poshumano que se plantean en la novela, leyendo los pasajes narrativos en que está implicado el juego de metáforas y

15 Sin coma antes de pero en la edición de Malpaso. 
motivos vinculado a este horizonte, que tan estrechamente ligado ha aparecido al género de la ciencia ficción. ${ }^{16}$

Hay que aclarar que si bien hay pocas referencias a híbridos tecnológicos futuristas o no son vigentes pactos de verosimilitud fantacientíficos, la reflexión por la problemática relación de los cuerpos y las mentes, como decíamos, alcanza aquí una excelente formulación: por un lado, la novela construye un hormiguero de cuerpos-desecho, retenidos en una cárcel, por medio de la que Paz Soldán nos ofrece una distopía arraigada en la realidad de su país; por otro, determinados personajes aparecen construidos de acuerdo con formas de subjetividad que traducen o alegorizan los modos de funcionamiento de medios tecnológicos.

La enfermedad ha sido un tópico muy utilizado por Paz Soldán con anterioridad -el cáncer, por ejemplo, en varios cuentos de Desencuentros (2004), en Sueños digitales (2000), El delirio de Turing (2003) o Los vivos y los muertos (2009) _, si bien nunca de manera tan protagónica como en esta novela. Aquí, la peste, castigo divino desde la literatura clásica y consecuencia de los pecados (religiosos o laicos) del hombre a lo largo de la historia de Occidente, aparece en el cuerpo social, como pandemia, cuando una cultura o civilización determinadas opta por abandonarlo.

Esta es la hipótesis básica que — a mi juicio- conecta la novela con el cuestionamiento del paradigma utópico de numerosas aproximaciones a lo poshumano, un concepto que podríamos definir como un paradigma cultural que emana de la relación que los seres humanos establecemos con la tecnología, desde el momento en que transferimos a nuestra relación con las máquinas parte de nuestra identidad, incorporando la tecnología a nuestro modo de concebir nuestros cuerpos o nuestra subjetividad.

Resulta necesario, llegados a este punto, pensar cuál es el estatuto del cuerpo desde el horizonte teórico de lo poshumano y examinar qué sentido tiene el modo en que los cuerpos son presentados en la novela, que lleva a vincularlos a la noción de "desecho".

16 El propio Paz Soldán, en un intercambio de correos electrónicos que hemos podido mantener, me anuncia que una primera versión de la novela transcurría en Iris, y versaba sobre la infancia de Reynolds, militar psicótico que aparece tanto en Iris como en Las visiones. No convencido de continuar explorando ese universo narrativo, decidió reescribir la novela ambientándola en Bolivia. 
Algunas de las más importantes aportaciones críticas a este paradigma estuvieron ligadas, en los años ochenta y noventa, con más o menos precauciones, a una visión utópica respecto de los efectos que la hibridez tecnológica ejercía sobre el cuerpo o la identidad. Por ejemplo, en las teorías ciberfeministas de Haraway (1991) o Hayles (1999), lo poshumano habilitaba una potencial superación del sujeto liberal patriarcal de la modernidad, destinado a controlar la naturaleza. En un mismo sentido, teóricos de la cibercultura, como Nick Bostrom (2003), habían imaginado posibilidades utópicas para un horizonte poshumano, ya abierto como posibilidad de un transhumanismo futuro, ya como una conexión de mentes, cuerpos y máquinas, que asociaban el concepto a nuevas identidades que permitían pensar lo humano más allá del idealismo dualista de la modernidad, un horizonte que, además de deseable, garantizaba la supervivencia de la especie. Puestos a especular, en un futuro más o menos lejano, la superación de los límites corporales resolvería, a decir de Bostrom (2003), el problema de nuestra dependencia de la Naturaleza, disolviendo o aminorando los efectos de la distopía ecológica hacia la que parecemos abocados.

El horizonte poshumano es, como nos recuerda Braidotti, el de un continuum naturaleza-cultura que hoy han disuelto sus fronteras (cfr. Braidotti, 2014), y esto, en su opinión, no ha de ser en absoluto leído negativamente. En ese sentido, Hayles (1999) ya había apuntado $^{17}$ que experimentar la crisis de una conciencia asociada a la corporeidad como pérdida suponía aferrarnos a ideologías respecto del individuo que encumbraron al sujeto liberal de la modernidad, un sujeto responsable de muchos de los males que nos han traído hasta aquí y, en cualquier caso, difícilmente sostenible en el umbral del siglo XXI.

Teóricos como Clark hablaban de "natural born cyborgs" (2003), en la medida en que todos los seres humanos, de una u otra forma, participamos de un poshumanismo en devenir, y esta idea de poshumanización como tendencia de nuestra especie vuelve evidente algo que subrayaba el sociólogo Brian Turner:

17 De un modo que recuerda a los argumentos de Vattimo para abrazar el nihilismo contemporáneo como oportunidad posmetafísica (cfr. Vattimo, 1990). 
[...] cada época [...], por la que el Hombre transforma la naturaleza con la tecnología, es también un periodo en que la naturaleza del Hombre se transforma. [...] cada periodo da lugar a [...] un nuevo cuerpo (1994, p. 21).

Como nos recuerda Le Breton, al menos desde los años sesenta, el individualismo moderno, los medios de masa, la medicina y la tecnología coadyuvan a la articulación de un nuevo dualismo que separa hombre de cuerpo, y permite empezar a pensar como posible una frase como es la de "liberación del cuerpo" (cfr. Le Breton, 2002, p. 9).

Según Haraway, a fines del siglo xx —más aún en nuestro siglo— el cíborg nos está hablando de nuestra propia ontología (cfr. Haraway, 1991). Es más, como señala Alba Rico, la relación que establecemos con nuestros cuerpos define lo que nos hace humanos, en tanto única especie que "tiene cuerpo en la medida en que está siempre huyendo de él” (2017, p. 52).

Este deseo de dejar atrás el cuerpo se acompaña, paradójicamente, de una irremediable nostalgia. Como apuntaba Fernando Broncano, si el cíborg es la consecuencia lógica del devenir de nuestra especie, también lo es caer en ese viaje en dirección opuesta a la naturaleza, en una melancolía insalvable (cfr. Broncano, 2009) de la que es fruto buena parte de la literatura distópica del siglo Xx.

En cualquier caso, sea leído como una consecuencia de lo humano, sea entendido como una ruptura epistémica que cierra un modo de concepción del self, el horizonte poshumano no parece ser un post más o una mera moda intelectual. Conviene tomarlo en serio.

Éric Sadin nos plantea un horizonte donde el sujeto humanista, que hasta ahora mantenía un tipo de relación con las máquinas como extensiones de los sentidos y capacidades humanas, tiene las horas contadas, en favor de una humanidad algorítmicamente asistida, que verá la necesidad de convivir con vidas artificiales no antropomórficas, en muchos sentidos infinitamente más capaces que los humanos:

Vivimos en los tiempos augurales de una omnisciencia y una omnipotencia tecnológicas. Experimentadas de modo indefinido, suscitan sentimientos de admiración más o menos formulados tanto como una fe ambiente en un re-encantamiento posible del mundo, en beneficio de 
virtudes de apariencia salvadora o mágica. Es la delegación expansiva del poder otorgado a la inteligencia computacional, que no limita su dimensión de soberanía al ámbito de nuestras acciones, sino que se despliega correlativamente bajo una forma simbólica, imponiendo con suavidad sus cualidades literalmente sobrehumanas en contra de toda percepción histórica de alienación. Es el gran vuelco contemporáneo, sobre el que no sabemos si deriva de una nueva relación positiva y abierta con la techné, deconstruyendo al pasar numerosas oposiciones ancestrales, o si es el testimonio de otra dinámica de sujeción, esta vez más discreta o más perversa (Sadin, 2017, pp. 87-88).

Entre la fascinación y el miedo, la relación con las máquinas que vislumbra Sadin nos sitúa en un estadio subordinado que, en el peor de los casos, podría resultar, no ya poshumano, sino antihumano. No obstante, aunque no interpretemos como anti ese post, las preguntas para resolver son muchas. Entre ellas, como apunta Naief Yehya (2012), está la de cómo se resuelve la lucha de clases. Este es el territorio en el que se ubica buena parte de la ciencia ficción distópica del siglo XXI, que plantea este tipo de preguntas hoy acuciantes: ¿qué clases o grupos controlarán el proceso de devenir poshumanos? ¿Quiénes lo están controlando de facto o lo han hecho en cada momento histórico?

Incluso, para algunas recientes aproximaciones ecofeministas a lo poshumano, coincidentes en valorarlo como paradigma cultural postantropocéntrico ${ }^{18}$ que, relativizando el peso del constructo moderno falogocéntrico y eurooccidental, permite atender a otras voces silenciadas por el humanismo clásico, el capitalismo avanzado también "genera una forma perversa de lo posthumano, en la medida en que cercena toda interacción humana y animal [...] y convierte a la vida en sí misma en el capital fundamental" (Braidotti, 2014, p. 11). Si pensamos en la película Elysium, de Neill Blonkamp (Baden-Powell, S. et al. y Blonkamp, 2013), puede entenderse bien esto que digo. En palabras del siempre visionario Mark Dery:

Las visiones de un ciberéxtasis son una seducción mortal que aleja nuestra atención de la destrucción de la naturaleza, de la descomposición

18 Pienso en aproximaciones como las de Braidotti, para quien lo poshumano puede pensarse una "brújula" para "indagar en los nuevos modos de comprometerse con el presente de manera no reduccionista, crítica, pero no nihilista" (Braidotti, 2014, p. 9). 
del tejido social y del abismo cada vez mayor entre la elite tecnocrática y las masas con salario mínimo. El peso de los problemas sociales, políticos y ecológicos hará que el despegue posthumano que deje atrás la biología, la gravedad y el siglo xx acabe estrellándose de nuevo contra la Tierra $(1998$, p. 24).

¿Cuál es la lectura que propone la obra de Paz Soldán del estatuto del cuerpo a la luz de estas discusiones? Sin duda, la visión que encontramos en la mayoría de los pasajes en que se tematizan identidades que podemos vincular con este paradigma en sus novelas es, en principio, muy pesimista. Poshumanismo y capitalismo aparecen asociados de modo mayoritario, coadyuvando a la destrucción del sujeto.

De sus ficciones de la última década y media se desprende una visión de lo poshumano en la que el cuerpo continúa revelándose como un problema, como la metáfora adecuada para mostrar lo que se destruye o entra en crisis con el neoliberalismo, fuerza que promueve la transformación del estatuto identitario de los personajes.

En Los días de la peste, por ejemplo, el funcionamiento del mercado neoliberal se representa metonímicamente en la Casona, una maqueta, cárcel-mercado, identificada con el principio de realidad en la novela. Como precisa Rigo en una ocasión, "Todo en la Casona era billete, quivo, tela, moneda, pesos” (Paz Soldán, 2017a, p. 88). Pero, una vez más, esta identificación no es nueva. Al igual que ocurre en Los días de la peste, el tratamiento del binomio enfermedad/ mercado recorre la tradición de la narrativa pestífera del siglo xx. Precisamente, en el libro de Camus, intertexto de referencia obligada para Paz Soldán, señala a este propósito el narrador la medida en que el cuerpo enfermo del hombre entabla una conflictiva relación con el mercado:

Un enfermo necesita alrededor blandura, necesita apoyarse en algo; eso es natural. Pero en Orán los extremos del clima, la importancia de los negocios, la insignificancia de lo circundante, la brevedad del crepúsculo y la calidad de los placeres, todo exige buena salud. Un enfermo necesita soledad. Imagínese entonces al que está en trance de morir como cogido en una trampa, rodeado por cientos de paredes crepitantes de calor, en el mismo momento en que toda una población, al teléfono o en los cafés, habla de letras de cambio, de conocimientos, de descuentos (Camus, s. f., p. 2). 
Este diagnóstico no ha hecho más que agravarse, como venimos señalando. Como apunta Alba Rico, la aceleración de nuestras sociedades y economías líquidas ataca de una manera definitiva al cuerpo, depósito de un tiempo que se opone al tiempo eucrónico del capitalismo neoliberal tecnológico. ${ }^{19}$

El mercado neoliberal ejerce una presión mayúscula sobre los cuerpos y, como parte del mismo proceso, transforma en desecho y arrincona aquello que no puede integrar en su circuito. El cuerpo, un depósito de tiempo, es, a la vez, un "medio de fuga" y un "obstáculo para ir más deprisa [...]” (Alba Rico, 2017, p. 56). Por eso el hambre, el aburrimiento y la enfermedad, atributos por excelencia del cuerpo, nos fuerzan, apunta Alba Rico (2017, p. 56), a volver a mirarlo en su obscena materialidad, por mucho que la cultura popular y los medios fetichizen, manipulen o nieguen su presencia, por mucho que el sistema pretenda reabsorber, reciclar o reprimir los desechos en el momento histórico del fin de las cosas.

El cuerpo es analizado en la novela como un desecho dejado atrás y, como apunta el sociólogo Gabriel Gatti, quizás los desechos o la basura definan mejor el estatuto sociológico de nuestro tiempo que la pulcritud inmaterial de las redes:

Pienso que la basura es una imagen útil para hablar de la disociación entre las cosas y las palabras o, si se quiere, para hablar de la paradójica articulación entre unas y otras, entre materialidad y representación, en la sociedad contemporánea. Resumo entonces: si la pregunta de este escrito se aplica al soporte material de las representaciones que ordenan la realidad social, la respuesta, tan paradójica como esa realidad sobre la que quiere indagar, se encuentra sondeando en los estercoleros de la modernidad, en la basura, esa materia disociada de sus sentidos (Gatti, 2009, p. 2).

La mirada al cuerpo mortal desde su obsolescencia y degradación, entendiéndolo como desecho, como materia "disociada de su sentido", es un leitmotiv de la narrativa de Paz Soldán, en la que una de las metáforas más productivas es el zombi. Leídos desde el zombi, los reclamos del poshumanismo se vuelven distópicos siempre.

El mito del zombi nos hace conscientes de lo atados que estamos a la fragilidad de nuestros cuerpos. Vueltos definitivamente zombis,

19 En términos de Dery, "velocidad de escape". 
devendríamos quizás en poshumanos, o tal vez en no humanos, pero dejaríamos de ser sujetos.

El zombi, contracara apocalíptica de cualquier utopía poshumana, nos permite "acceder al mundo que nos rodea desde una visión compleja de la propia cultura” (Fernández Gonzalo, 2011, p. 194), visibiliza los modos en que el biopoder nos deshumaniza y relega a la esfera de lo inerte. Dicho en palabras de Sarah Lauro y Karen Embry:

The zombie, we feel, is a more pessimistic but nonetheless more appropriate stand-in for our current moment [...] in a global economy, where we feed off the products of the rest of the planet, and, alienated from our own humanity, stumble forward, groping for immortality even as we decompose. [...] Thus, reified as a part of the process of production, the subject has already bled into the object: we are already dwelling in the zombie's interzone (2008, p. 93).

Determinados motivos asignables al imaginario de género - fundamentalmente del terror gótico- permean la estética realista que la crítica ha celebrado en Los días de la peste. El motivo del zombi resulta visible en una de las primeras escenas de la novela, precisamente cuando Rigo ingresa a la cárcel: "Traspusimos el portón de entrada y fuimos llevados a una oficina con una foto enmarcada del Gobernador y afiches de películas de zombis" (Paz Soldán, 2017a, p. 14). A partir de esa referencia, el concepto se disemina por la novela. El "loco de las bolsas" recupera el motivo en su discurso. A su vez, este histriónico personaje puede pensarse como una suerte de coro trágico (tragicómico, quizás), ${ }^{20}$ al estar construido a partir de retazos de voces ajenas provenientes de la radio y la televisión.

El loco, personaje esquizoide, construye su discurso como un pastiche que hila diferentes referencias pop - musicales y televisivas- de los años sesenta, setenta y ochenta, cosidas con fragmentos reconocibles de El padre mío (1989), de Diamela Eltit. El personaje funciona en la novela como memoria desmemoriada de la colectividad, recordando a todos una muerte que parece haber tenido lugar hace tiempo:

20 Paz Soldán afirma que se inspira en un vagabundo conocido en su ciudad natal, en su juventud, que precisamente llevaba bolsas en manos y pies. 
Lávense las manos, no se toquen, no cojan. Nos vamos a morir de nuevo. [...] Tomen harta agua. Coman bien, pero limpien su comida. Fuiste mía un verano, solamente un verano. Cómo olvidar tu nombre [...] Y no bailen, porque si no nos vamos a morir de nuevo (Paz Soldán, 2017a, p. 215).

Por otro lado, a nivel estético, el influjo del cine de terror es evidente en las descripciones espectacularizadas de los contagiados por ese "virus filamentoso" desconocido, que remite, de nuevo, a esos afiches iniciales, pese a no llegarse a traspasar en ningún momento el verosímil realista:

La Paciente Uno se había levantado de la cama y hecho caer el aparato conectado al catéter por el que se le administraba el suero intravenoso. Las manchas rojizas en el cuello se habían ampliado [...] moretones que invadían su pecho y partes de la cara. Gotas de sangre le salían por la nariz y por las orejas. [...] dio dos pasos [...] se desplomó. En el suelo sufrió convulsiones. [...] Tenía las pupilas dilatadas y se estaba mordiendo la lengua [...] Los músculos del rostro habían perdido consistencia, cansados de sostenerlo, y todo chorreaba, como si el cuerpo estuviera cambiando de estado, dejando de ser sólido. Lo que más impresionaba a Yandira era que la paciente estuviera llorando sangre (Paz Soldán, 2017a, p. 125).

$\mathrm{Si}$, como nos advierte Alba Rico, "la tecnología deja virtualmente atrás el cuerpo como un antepasado más lento [...]" o "un residuo" (Alba Rico, 2017, p. 59), Los días de la peste puede leerse como el apeadero de los cuerpos - los despojos - que han venido dejando atrás todos los personajes en prácticamente todas sus novelas anteriores. También los de esta novela. En este sentido, resulta sintomático el modo en que todos los personajes huyen de sí mismos mediante las diferentes herramientas a su alcance, intracoporales, intercorporales o extracorporales o exosomáticas (cfr. Alba Rico, 2017): el consumo de tonchi; las pastillas lisérgicas; el sexo compulsivo con extraños; las ceremonias rituales de Ma Estrella con sustancias alucinógenas (como en las que participa Celeste, la esposa del gobernador Otero); los tatuajes con los que fantasean todos los personajes (una escritura que vuelve legibles los cuerpos sin sentido); el mercadeo con prótesis ortopédicas que planean Lillo y el Tullido; el bótox y la cirugía estética que consumen Celeste, El Forense o la doctora Tadic; el visionado 
compulsivo de porno a cargo de Hinojosa, el jefe de los guardias; la disolución esquizoide en una comunidad interior al propio "yo" siguiendo el dictado de una secta de Rigo; la violencia extrema y gratuita de Krupa; la negación del cuerpo cubriéndose obsesivamente el rostro, los pies y las manos con bolsas de plástico (el "loco de las bolsas"); la evasión de lo real por medio de juegos de mesa piratas con el irónico nombre de Pandemia; los simuladores virtuales donde gobernadores y jueces juegan a la guerra y ensayan la destrucción de mundos imaginarios, etc.

Por eso, la prisión es elegida en la novela como forma adecuada para proporcionar una reflexión sobre la condición del cuerpo hoy. Como apunta David Le Breton, en situaciones límite de confinamiento o privaciones, el cuerpo adquiere una existencia dual; la vida cotidiana se vuelve, entonces, una lucha contra el propio cuerpo, que adquiere una autonomía que lo convierte en el "lugar geométrico de toda servidumbre y de todos los sufrimientos" (Le Breton, 2002, p. 94), cayendo la subjetividad en una ensomatosis, o caída en el propio cuerpo, que adquiere la cualidad de lo desechable.

A pesar de sus esfuerzos, los personajes que habitan en Los Confines - en palabras de Rigo, "una multitud que era un desperdicio" (Paz Soldán, 2017a, p. 34) — acaban cayendo o deshaciéndose en la materialidad de cuerpos, heces, sangre, enfermedad y muerte.

Como venimos sosteniendo, figuración distópica y desecho son los dos rasgos más relevantes de la estética pazsoldaniana en la novela, que muestra o visibiliza el funcionamiento de un capitalismo a escala, la prisión, una institución fallida donde el Estado se cancela y todos los derechos individuales pasan a manos privadas, se compran y se venden.

\section{Dos articulaciones de lo poshumano: hipercuerpo y subjetividad en red}

Como evidencian los ejemplos que acabo de analizar, las aproximaciones más comunes al conflicto virtualidad/corporeidad en la narrativa de Paz Soldán a menudo aparecen ancladas al humanismo antropocéntrico, y ello es un lugar común sobre todo en su narrativa de los años dos mil (cfr. Montoya Juárez, 2011). Así, en novelas como 
Sueños digitales, El delirio de Turing y en muchos de sus cuentos se revela, como ha señalado Andrew Brown, un poshumano profundamente humano (cfr. Brown, 2010). No obstante, tanto en Iris como en Los días de la peste esta mirada sobre el problema adopta fórmulas más variadas y complejas. Algunas de las más originales apuntan a la idea de las redes o tienen la Red como modelo y, en el caso específico de esta novela, excepcionalmente, pueden vincularse con cierto posantropocentrismo: por un lado, la Casona, personaje colectivo y verdadero protagonista del texto, parece constituirse como un hipercuerpo; por otro, uno de los personajes, Rigo, replica esta estructura en red en el interior del individuo.

El filósofo Pierre Lévy analizaba los efectos sobre lo corporal de los procesos de virtualización y las dinámicas interioridad-exterioridad que las nuevas tecnologías en el campo de la medicina han hecho posibles, empleando la metáfora de la cinta de Moebius. Apunta Levy a un proceso de exteriorización del cuerpo, multiplicado exponencialmente con el desarrollo de la tecnología. Según Lévy, se ha hecho público lo interno y lo público se ha vuelto privado. El mercado de prótesis tecnológicas, las redes médicas de material biológico trasferible entre los sujetos, el desarrollo de órganos a partir de células, la edición genética, son ejemplos del modo en que se vuelven difusos los límites entre lo externo y lo interno, entre lo natural y lo cultural, en la concepción del cuerpo. Esto es lo que Lévy describe con el término de "hipercuerpo", que afecta en primer lugar a lo cultural, pero también a lo biológico mismo:

La carne, la sangre, puestas en común, abandonan la intimidad subjetiva y pasan al exterior. Pero esta carne pública regresa al individuo trasplantado, al beneficiario de una transfusión, al consumidor de hormonas [...] hoy en día nos asociamos virtualmente en un cuerpo articulado con quienes participan en las mismas redes técnicas y médicas. Cada cuerpo individual se convierte en parte receptora de un inmenso hipercuerpo híbrido y mundializado (Lévy, 1999, p. 30).

Las ideas de Lévy tienen su complemento en lo que Balaguer propone como "hipocuerpo". Afirma Balaguer que, paradójicamente, con la llegada de esa nueva escala de la hipercorporalidad, y su correlato, la inteligencia artificial en red, el estatuto del cuerpo individual se ve presionado de forma inédita: "La noción de hipocuerpo más 
que nada se corresponde con una vivencia de reducción del cuerpo a una categoría limitada" (Balaguer, 2002), consciente, por tanto, de una nueva obsolescencia o debilidad.

Si aplicamos algunas de estas ideas a la novela, vemos cómo la Casona puede leerse muy bien como un hipercuerpo, en la medida en que absorbe o pone en circulación el material biológico de los diferentes seres que la habitan, donde la idea de la conectividad no necesariamente pasa por la de una comunicación efectiva a escala humana, sino que más bien funciona según una escala matérica que concilia conectividad e incomunicación. La analogía más evidente está en el mismo virus que se expande por la prisión, que obliga a tratamientos intravenosos, transfusiones sanguíneas en la sala del cólera, intercambio de fluidos en los numerosos episodios donde los personajes tosen, vomitan o sangran unos sobre otros: "Él le dio unas palmadas en la espalda y ella tosió en su cara. Él retrocedió con un gesto de asco y se limpió la cara con un klínex. Hizo anotaciones en un papel. Se lo dio a la enfermera" (Paz Soldán, 2017a, p. 41). O bien: "Ayer yo había encontrado a Oaxaca meándolo" (Paz Soldán, 2017a, p. 20). Otro ejemplo, el negocio que pretenden implantar Lillo y el Tullido en la Casona: un mercado de prótesis corporales low tech para los presos.

El paratexto inicial del biólogo Jacob Uexküll — "todo en el mundo biológico es armonía, todo es melodía” (Paz Soldán, 2017a, p. 7) - se convierte en una clave de sentido que proyecta la idea de lo postantropocéntrico sobre toda la novela. Del griego ó $\rho \mu$ oví $\alpha$, la harmonía implica "juntura", "ensamblaje" de lo diverso, de acuerdo con la definición del Diccionario de la lengua española de la Real Academia Española (2017). En la novela, el autor se complace en insertar, en cada uno de los pasajes, elementos provenientes de universos perceptivos que cohabitan en la cárcel. En todos los pasajes hay referencias a presencias animales aparentemente irrelevantes o silenciosas: "De un corte manaba sangre sobre la ceja izquierda [...] los murciélagos sobrevolaban el patio" (Paz Soldán, 2017a, p. 15); "El juez lo condujo a su escritorio. Pasaron junto a terrarios con dragones barbados, salamandras verdes y varanos de ojos escurridizos" (Paz Soldán, 2017a, p. 43); "La brisa se llevaba pedazos chamuscados de papel de periódico como alas de murciélagos" (Paz Soldán, 2017a, p. 189). Esas presencias no se comunican con los individuos, aunque de alguna manera se 
hallen conectadas con ellos y, a su vez, integradas al circuito del ente colectivo que es la prisión.

Sobre estas presencias, la novela no proyecta construcciones o imágenes performativas que les den sentido, no se las "traduce" de acuerdo con esquemas humanos, sino que mantienen un cierto hieratismo. Precisamente, el personaje que explicita una subjetividad más fragmentada — un "yo" asambleario, de acuerdo con la feliz expresión de Mora (2017), que funciona como un narrador testigo que da voz a las diferentes partes de su propio cuerpo (la piel, el cuerpo, la voz, los ojos, los putapariós, etc.) — es quien mejor se adapta y atisba el funcionamiento de este hipercuerpo. Rigo es el único personaje que procesa simbólicamente la multiplicidad de universos interiores que coexisten en la cárcel, a través de una religión, la Transfiguración, tratando de integrar voces interiores y exteriores a él, en una subjetividad múltiple y atormentada.

Si el modelo de la des-memoria del "loco de las bolsas" eran la radio y la televisión, la memoria de Rigo funciona como la descarga aleatoria de datos de la red. En su discurso "recibe" fragmentos de la Exégesis, un libro sagrado que incluye algunas citas levemente modificadas de Cartas biológicas a una dama, de Uexküll (1941):

Son iguales los miles de mundos circundantes de hombres y animales, igual el de unos sujetos que el de las ostras jacobeas, que no acechan en su mundo más que un determinado movimiento, que actúan como una señal a la que responden aleteando los largos flecos olfativos ( $\mathrm{Paz}$ Soldán, 2017a, p. 87).

La cita es relevante, porque una de las ideas productivas en la poética de la novela es, precisamente, esta noción de "mundo circundante". Para Uexküll (1941), los diferentes seres vivos reaccionan a estímulos específicos de acuerdo con su diseño biológico, configurando un sistema de percepción, de tal modo que aquellos estímulos para los que no están programados permanecen invisibles o ausentes de su mundo circundante. Por eso, el campo semántico de la visión/ ceguera, de lo que se percibe y toma cuerpo, y de lo invisible o fantasmagórico, resulta una clave de sentido.

Baste citar algunos ejemplos: los hijos de los guardias y los presos se reúnen en la Plazuela Ciega; los doctores no son capaces de hallar una explicación o una cura para el virus, al que juzgan "un fantasma”, 
y a Hinojosa, cuando baja al quinto patio en que ocultan a un preso político a los ojos del Presidente, en un pasaje que hace pensar en una leyenda minera (alguna de, por ejemplo, Vicente Terán Erquicia $\left.{ }^{21}\right),{ }^{22}$ se le aparece un fantasma que no llega a ver:

Krupa lo miró asombrado al llegar a la sala. Estás como si hubieras visto un fantasma, dijo. Lo peor es que no lo vi, respondió Hinojosa. Esos son los más terribles, Krupa habló como si supiera del tema (Paz Soldán, 2017a, p. 218).

En la novela, esta idea de mundos que conviven sin percibirse tiene su analogía en el gesto poético de tematizar reiteradamente iteraciones fractales o recursivas, que trasladan la idea de que, por ejemplo, la misma cárcel sea una esfera contenida en otra cárcel, a su vez contenida en otra cárcel, y así hasta el infinito: "Odiaba a esos resignados, casi todos, que decían que en la Casona se vivía mejor que afuera. [...] La cárcel era la cárcel era la cárcel” (Paz Soldán, 2017a, p. 65). Se trata, entonces, de lo carcelario como definición misma del mundo, de acuerdo con el dictum de Giorgio Agamben (cfr. Agamben, 2006): "¿Y qué hacemos con los presos? ¿Los guardias? ¿El Gobernador? Trasladar a todos a una nueva prisión, construida para resolver el problema. Esa prisión se llamará la Casona" (Paz Soldán, 2017a, p. 284).

Esta idea de hipercuerpo-mercado, que absorbe la vida y niega la comunicación entre sus especies, se ve reforzada en las referencias reiteradas al edificio como un ente supraindividual que funciona como un ser viviente, de acuerdo con una volición ciega o incognoscible:

Se detiene cerca de una ventana cerrada y escucha un silbido que golpea las paredes, parecido al sonido del viento cuando choca contra una puerta de metal o al del mar embravecido golpeando contra las rocas. Uiiih, uiiih, uiiiih. Provoca angustia, como si cien demonios estuvieran intentando forzar una puerta para escaparse de su guarida. Lya quiere que el silbido desaparezca pero este sale de las paredes, como si fueran su respiración, y los envuelve (Paz Soldán, 2017a, p. 78).

21 Una de las leyendas más célebres de cuantas hacen referencia a demonios subterráneos es "La leyenda de El Tío en el socavón Caracoles", publicada en los Cuentos y leyendas (1969) de Vicente Terán Erquicia, recogida en el estudio de Antezana sobre la narrativa minera boliviana (cfr. Antezana, 2011).

22 Los ecos de la narrativa minera son más influyentes en Iris. En Los días de la peste la referencia es menos precisa. Sobre esta cuestión remito a un trabajo previo: Montoya Juárez (2017). 
El ruido del edificio se vuelve audible, sobre todo, en un punto concreto, un interior que es, a la vez, exterior: el cuarto maldito, donde nadie quiere pasar la noche, pues cíclicamente en el suelo reaparecen las manchas de sangre de un célebre inquilino (un cuerpo desaparecido, de nuevo), "El Tatuado", un líder indígena ejecutado cien años atrás. En "Los silbidos", como le ocurre a Juan Preciado, el protagonista de Pedro Páramo (1955), en una novela que inicialmente iba a llamarse Los murmullos, también parece posible oír el eco de las voces de los muertos, e incluso la voz de lo no humano, de la materia misma:

Dijo la voz, no tengas miedo, piel, es el edificio, que no sabe hablar y habla así. Es el ruido del mundo, que habla a través del edificio. Piel, sé una con ese ruido. Eres el mundo y ese ruido también lo haces tú (Paz Soldán, 2017a, p. 87).

Sin el concurso de la presencia temática de la alta tecnología, Paz Soldán, en Los días de la peste, construye una subjetividad poshumana articulada en una serie de puntos nodales o grumos de sentido en una red desjerarquizada, una red que se explora en lo macro, como hipercuerpo que refleja la condición de la vida en el mercado-prisión que es la Casona, y en lo micro, en la subjetividad del personaje de Rigo, en quien se manifiesta una identidad descentrada donde "lo humano", en tanto categoría desde la que se piensa el sujeto, se pone radicalmente en crisis:

A esa comunidad que éramos nosotros se habían añadido los putapariós. Debíamos ser hospitalarios con ellos, por más que fuera difícil. Las manos, la piel, la voz, eran parte del grupo, al igual que los bichos invisibles que anidaban en el cuerpo. Todos, criaturas dentro de la criatura, un mundo dentro de otro mundo dentro de otro mundo, así hasta el infinito (Paz Soldán, 2017a, p. 100).

\section{A modo de conclusión}

Como he señalado, Los días de la peste es, entre otras cosas, una excelente reflexión sobre la condición de desecho que adquieren los cuerpos hoy, sobrepujados por la velocidad acelerada del neoliberalismo en el siglo XxI. En la novela se construye un ente colectivo que habitan las identidades sombrías de personajes que castigan o se evaden de la prisión de sus propios cuerpos, cuerpos que se deshacen, 
abismándose en ellos las promesas utópicas de lo poshumano, un concepto arraigado fuertemente, en el tratamiento que de ello hace el autor, a la presión que el neoliberalismo ejerce sobre la subjetividad.

El autor boliviano, en estos últimos años, abandonando toda fascinación por los fuegos artificiales posmodernos o digitales del primer McOndo, proyecta una actitud vigilante, atenta a cómo lo local emerge y se transforma, tras las promesas fallidas de la globalización, o a cómo, a pesar de los brillos de cierta teoría del poshumanismo, los cuerpos y su circulación persisten como un problema decisivo de nuestro tiempo. Los días de la peste da buena cuenta de este sólido proyecto narrativo.

Pero, al mismo tiempo, en la novela se plantea al menos un hallazgo, Rigo, de una mayor complejidad. El suyo es un proyecto que se revela ciego, suicida e imposible, en el que quizás podríamos leer un modo distinto de articular literariamente la identidad poshumana. En Rigo, tal vez pueda leerse, como en un espejo deformado, el esbozo de un desiderátum para el arte o la literatura. Se trata de una no resuelta y mínima valencia utópica del concepto, a contrapelo del pesimismo general de la novela, una utopía formulada como deseo de alcanzar una iluminación en ese horizonte distópico, anclado a una dura realidad social boliviana, no únicamente por la vía de un refugio en la religión, esto es, en lo simbólico o en lo cultural, sino también por la vía de un radical descentramiento del sujeto antropocéntrico. Una voluntad de comunicación que rebase los compartimentos estancos entre especies y alcance a superar la ceguera limitante con la que confrontamos un mundo caótico. ¿Una tarea, acaso, para el arte o la literatura en el siglo XxI?

A mi modo de ver, tal vez sea esta la lectura más rica que pueda hacerse de la productividad de la metáfora de lo poshumano en la narrativa de Paz Soldán: la que afecta al modo en que, en cada novela, el autor repiensa el quehacer artístico, su supervivencia o su posibilidad de cartografiar políticamente el presente 


\section{Referencias}

Agamben, G. (2006). HOMO SACER: El poder soberano y la nuda vida. Valencia: Pretextos.

Alba Rico, S (2017). Ser o no ser (un cuerpo). Seix Barral.

Antezana, L. (2011). Ensayos escogidos (1970-2010). La Paz: Plural.

Asimov, I. (1951). Foundation. New York: Gnome Press.

Baden-Powell, S. et al. (productores) y N. Blonkamp (director) (2013). Elysium [Cinta cinematográfica]. Estados Unidos: Media Rights Capital / QED International / Sony Pictures Entertainment (SPE) / TriStar Pictures.

Balaguer Prestes, R. (2002). El hipocuerpo: una vivencia actual que la virtualidad aún no puede eludir. Revista textos de la CiberSociedad, (2). Recuperado de http://www.ilhn. com/datos/practicos/datosestela/archives/003392.php

Benjamin, W. (2003). Experiencia y pobreza. Recuperado de http//www.archivochile.com/ Ideas_Autores/benjaminw/esc_frank_benjam0005.pdf.

Bostrom, N. (2003). The Transhumanism FAQ -A General Introduction-. Versión 2.1. Recuperado de https://nickbostrom.com/views/transhumanist.pdf.

Braidotti, R. (2014). Lo posthumano. Barcelona: Gedisa.

Broncano, F. (2009). La melancolía del ciborg. Barcelona: Herder.

Brown, A. J. (2010). Cyborgs in Latin America. New York: Palgrave McMillan.

Camacho, J. M. (2018). Religiosidad popular, mundo carcelario y pandemia en Los días de la peste de Edmundo Paz Soldán. Ponencia en Congreso. VII Congreso Internacional de Estudios Latinoamericanos de Olomouc. Universidad Palacký, Olomouc.

Camus, A. (s. f.). La peste. Buenos Aires: Libros Tauro. Recuperado de http://ww2.educarchile.cl/UserFiles/P0001/File/articles-106161_Archivo.pdf.

Carpentier, A. (1949). El reino de este mundo. México: E.D.I.A.P.S.A.

Cerruto, O. (1935). Aluvión de fuego. Santiago de Chile: Ediciones Ercilla.

Clark, A. (2003). Natural Born Cyborgs. Minds, Technologies and the Future of Human Intelligence. Oxford: Oxford University Press.

Clarke, A. C. (1955). La estrella. Infinity Science Fiction, s. d.

Darlymple, W. (2010). Nueve vidas. Barcelona: Kairós.

Defoe, D. (1969). Diario del año de la peste. Barcelona: Seix Barral.

Dery, M. (1998). Velocidad de escape. La cibercultura en el final de siglo. Madrid: Siruela.

Eltit, D. (1989). El padre mío. Santiago de Chile: Francisco Zegers Editor.

Fernández Gonzalo, J. (2011). Filosofía zombie. Barcelona: Anagrama.

Fisher, M. (2016). Realismo capitalista. Buenos Aires: Caja Negra Editora. 
Gatti, G. (2009). La materialidad del lado oscuro (Apuntes para una sociología de la basura). En G. Gatti, I. Martínez y B. Tejerina (Eds.), Tecnología, cultura experta e identidad en la sociedad del conocimiento (pp. 1-25). Leioia: Servicio editorial Universidad del País Vasco. Recuperado de https://goo.gl/a6pBDd

Goffman, E. (1972). Internados. Ensayos sobre la situación de los enfermos mentales. Buenos Aires: Amorrortu.

Gordin, M. D., Tilley, H., y Prakash, G. (2010). Introduction. En Utopía/Dystopia: Conditions of Historical Possibility (pp. 1-18). Princeton: Princeton U. P. Recuperado de http:// press.princeton.edu/chapters/i9188.pdf

Haraway, D. (1991). A cyborg manifesto. En Simians, Cyborgs and Women: The Reinvention of Nature (pp. 148-181). London: Free Association Books.

Hayles, K. (1999). How We Became Posthuman: Virtual Bodies in Cybernetics, Literature and Informatics. Chicago: University of Chicago Press.

Hebert, F. (1965). Dune. Radnor, PA: Chilton Company.

Iglesia, A. M. (2016, 17 de junio). Entrevista a Edmundo Paz Soldán. Eñe. Recuperado de http://revistaparaleer.com/actualidad/sala-de-lectura/entrevista-a-edmundo-paz-soldan-por-anna-maria-iglesia/

Jameson, F. (2000). Las semillas del tiempo. Madrid: Trotta.

Jameson, F. (2005). Archaeologies of the Future. New York and London: Verso.

Klein, N. (2007). La doctrina del shock. Barcelona: Paidós.

Lauro, S. J., y Embry, K. (2008). A zombie manifesto: The nonhuman condition in the era of advanced capitalism. Boundary 2, 35(1), 85-108. DOI: 10.1215/01903659-2007-027

Le Breton, D. (2002). Antropología del cuerpo y modernidad. Buenos Aires: Nueva Visión.

Lévy, P. (1999). ¿Qué es lo virtual? Barcelona: Paidós.

McLuhan, M. (1996). Comprender los medios de comunicación. Barcelona: Paidós.

Montoya Juárez, J. (2011). Arqueologías del presente: cuerpos y escritura en Los vivos y los muertos. En E. Ramos-Izquierdo (Ed.), Autour des écritures du mal (pp. 61-78). Paris, Île de France: ADELH - RILMA 2.

Montoya Juárez, J. (2013). Narrativas del simulacro: videocultura, tecnología y literatura en Argentina y Uruguay. Murcia: Editum.

Montoya Juárez, J. (2017). De Río fugitivo a Iris: poshumanismo, forma y discurso en la ficción reciente de Edmundo Paz Soldán. El Taco En La Brea, (6), 201-219. Dor: 10.14409/ tb.v0i6.6972

Mora, V. L. (2017, 31 de agosto). El yo asambleario de Los días de la peste. Diario de lecturas [Mensaje en un blog]. Recuperado de http://vicenteluismora.blogspot.com/2017/08/elyo-asambleario-de-los-dias-de-la.html 
Paz Soldán, E. (1998). Río Fugitivo. La Paz: Alfaguara, 1998.

Paz Soldán, E. (2000). Sueños digitales. Barcelona: Anagrama.

Paz Soldán, E. (2003). El delirio de Turing. Buenos Aires: Alfaguara.

Paz Soldán, E. (2004). Desencuentros. Buenos Aires: Alfaguara.

Paz Soldán, E. (2009). Los vivos y los muertos. Madrid: Alfaguara.

Paz Soldán, E. (2011). Norte. Barcelona: Random House Mondadori.

Paz Soldán, E. (2014). Iris. Madrid: Alfaguara.

Paz Soldán, E. (2016). Las visiones. Madrid: Páginas de Espuma.

Paz Soldán, E. (2017a). Los días de la peste. Barcelona: Malpaso.

Paz Soldán, E. (2017b, 1 de febrero). El Deber. Recuperado de https://www.eldeber.com.bo/ escenas/Edmundo-Paz-Soldan-y-Los-dias-de-la-peste-su-novela-20170201-0066.html.

Real Academia Española (2017). Diccionario de la lengua española. Recuperado de http:// rae.es.

Rulfo, J. (1955). Pedro Páramo. México: Fondo de Cultura Económica.

Sadin, É. (2017). La humanidad aumentada. Buenos Aires: Caja Negra Editora.

Turner, B. (1994). Los avances recientes en la teoría del cuerpo. REIS, (68), 11-40. Recuperado de http://www.reis.cis.es/REIS/PDF/REIS_068_04.pdf

Uexküll, J. (1941). Cartas biológicas a una dama. Santiago de Chile: Zigzag editora. Recuperado de https://issuu.com/echeverriapatricio/docs/cartasbiologicas

Vattimo, G. (1990) La sociedad transparente. Barcelona: Paidós, ICE de la Universidad Autónoma de Barcelona.

Virilio, P. (1997). Cibermundo, ¿una política suicida? Santiago de Chile: Dolmen.

Viscarra, V. (1981). Coba: lenguaje secreto del hampa boliviana. La Paz: Librería-Editorial Popular.

Yehya, N. (2012). Marionetas tecnológicas y cuerpos modificados: dos rutas concurrentes al cyborg. Literal: Latin American Voices, (19). Recuperado de http://literalmagazine.com/ marionetas-tecnologicas-y-cuerpos-modifi-cados-dos-rutas-concurrentes-al-cyborg/

Young, R. (2003). Marching Powder. Sidney, Nsw: Pan Macmillan. 